\title{
EXAMINING THE RESUlTS OF THE EXPERIMENTAL Solution with a Focus to Elastic Effect Area
}

\author{
Zdenka NEUWIRTHOVA ${ }^{1}$, Zuzana MARCALIKOVA ${ }^{2}$, Radim CAJKA ${ }^{3}$ \\ ${ }^{1}$ Department of Structures, Faculty of Civil Engineering, VSB - Technical University of Ostrava \\ Ludvika Podeste 1875/17, 70833 Ostrava - Poruba, Czech Republic \\ ${ }^{2}$ Department of Structures, Faculty of Civil Engineering, VSB - Technical University of Ostrava \\ Ludvika Podeste 1875/17, 70833 Ostrava - Poruba, Czech Republic \\ ${ }^{3}$ Department of Structures, Faculty of Civil Engineering, VSB - Technical University of Ostrava \\ Ludvika Podeste 1875/17, 70833 Ostrava - Poruba, Czech Republic
}

zdenka.neuwirthova@vsb.cz, zuzana.marcalikova.st@vsb.cz, radim.cajka@vsb.cz

DOI: $10.31490 /$ tces-2018-0002

\begin{abstract}
Problematic of soil - structure - interaction is subject of research for many years, however satisfactory accuracy of numerical models has not been achieved yet. Therefore, it is necessary to examine this phenomenon. For this purpose, special testing equipment was built at Faculty of Civil Engineering in Ostrava and series of experimental tests were performed. One of the tested slabs was chosen and its numerical model was created in computational program Ansys 18.0. Numerical model consists of two parts - slab and soil, connected with a contact element. From the test and the model data, maximal deformations and deformations trough the cross section of the slab were compared. This paper examines whether the Hooke's law is valid and can be used to express the test behavior and locate elastic effect area allowing linear modelling which can be useful for lowering computational time.
\end{abstract}

\section{Keywords}

Soil, slab, interaction, contact task, FEM, element size.

\section{Introduction}

Development of numerical methods and computational techniques allow solving challenging engineering tasks. One of these tasks is an interaction between a concrete structure and subsoil [1] - 3]. This problematic is solved for decades worldwide [4], - 7] but also in the Czech Republic 88 - 14. In the VSB - Technical University, in the Faculty of Civil Engineering is the interaction between the slab and the subsoil under research for a long time [11, 12]. To support the numerical research a testing device was designed to verify the numerical results. While using the device series of experiments were performed as well as subsequent numerical analysis [8], 10, 13, 14]. The soil structure interaction is a big area of interest of universities and companies [4], 6], 7], [15]. To solve the task, it is important to take into account also influence of physical and structural non - linearity. This problematic is solved by authors [5], [16] and also design codes deal with it [17, 18]. Using analytical methods only significantly simplifies solved problem and evaluated values are approximate. On the other hand, numerical analysis provides greater flexibility in the problem solving. This procedure requires huge amount of input parameters and experience how to successfully consider the complex behavior. There are many options how to solve nonlinear analyses, one of the possible options is using finite element method 2, [19]. There are a number of computational systems using the finite element method. One of them is Ansys which is selected for the calculations in the article. The finite element method makes possible to create a detailed computational and material models. This may take into account the actual behavior of the solved task. It is appropriate to define the elastic effect area where the linear model is valid by comparing to the experiment for better understanding of the subsoil behavior and more accurate nonlinear modeling. It also results to lower computational time in problematics where complex nonlinear model is not required. 


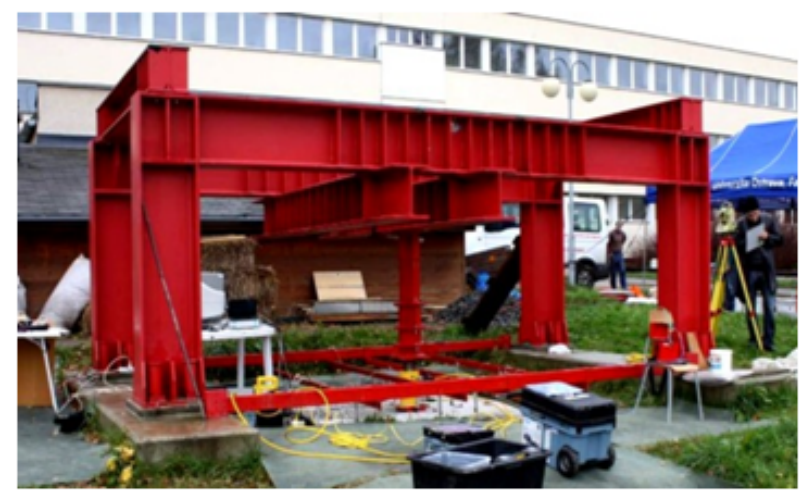

Fig. 1: Special test equipment Stand

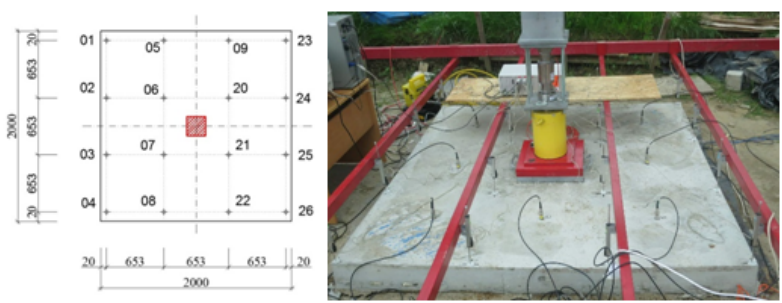

Fig. 2: Layout of extensometers during test

\section{Methods}

Special test equipment to support the research [3] was developedin the VSB - Technical University, in the Faculty of Civil Engineering. Once a test of functionality was done, set of tests were performed on the fibre concrete slabs with dimensions $150 \times 2000$ x $2000 \mathrm{~mm}$ with different amount of the fibers. The slabs were loaded through the area of $400 \times 400 \mathrm{~mm}$ and the deformations were measured in 16 nodes as described in Fig. 2 . Lading was caused by hydraulic piston and recorded by measurement panel together with deformation of slab.

One slab was selected to make a numerical model and observe the behavior from this set of experiments. As input parameters for numerical model geometry and parameters were selected same as was used in the experimental testing. Also some outputs like concrete characteristics enter the calculation.

\subsection{Output Parameters of Experiment}

Slab no. D10-G01 was selected from series of test made in the 2016. This slab consists of the plain concrete only without any reinforcements. Concrete type C $20 / 25$ was used. Few samples were produced together with the slab and tested in the laboratory and following characteristics were measured:

- average compressive strength of concrete (cube test) $f_{c, c u b e}=25.11 \mathrm{MPa}$,

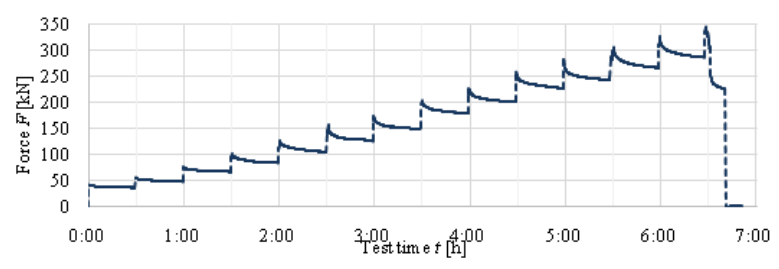

Fig. 3: Loading process during test
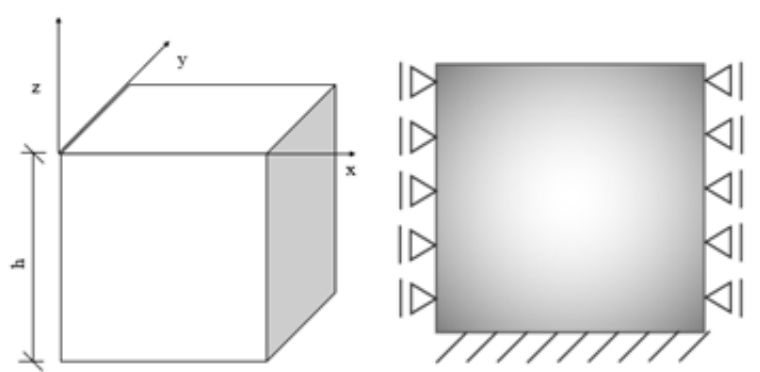

Fig. 4: Left - coordinate system; Right - boundary conditions

- average compressive strength of concrete (cylinder test) $f_{c, c y l}=20.03 \mathrm{MPa}$,

- average tensile strength $f_{t}=2.10 \mathrm{MPa}$,

- average elastic modulus $E=17000 \mathrm{MPa}$.

The slab was loaded in several steps until failure in 30 minute intervals. The loading process is shown in the Fig. 3 .

\subsection{Input Parameters of Numerical Model}

Numerical model consists of two parts - the slab and the soil (Fig. 5). Both parts are connected by a rough contact, thereby provides transfer only of compression effects, the tension cannot occur.A friction was neglected. The model consists of three dimensional 8 nodes elements with 6 degrees of freedom in each node. Boundary conditions were selected as follows (Fig. 4), a bottom part of the model is supported by fixed support, and sides are pinned.The finite element size was selected to size $0.5 \mathrm{~m}$ for the subsoil and 0.1 for the slab. The force was applied through the area of $0.4 \times 0.4$ in the middle of the slab according to the experiment. The soil model is based on the theory of elastic half space replaced by cube. The dimensions of the cube are same in all three directions with edge dimensions $h=$ $6 \mathrm{~m}$.Behavior of the soil model was characterized by the modulus of elasticity $E=35 \mathrm{MPa}$ and the Poisson coefficient $\mu=0.25$. Self - weight was neglected.

The force chart recorded during the test (Fig. 3) was simplified and represented with two values for each step - one at beginning and one at the end of step time 


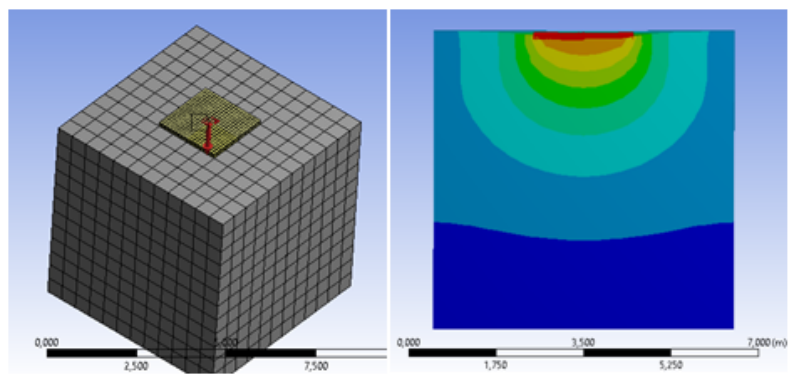

Fig. 5: Numerical model in Ansys - mesh (left), deformation (right)

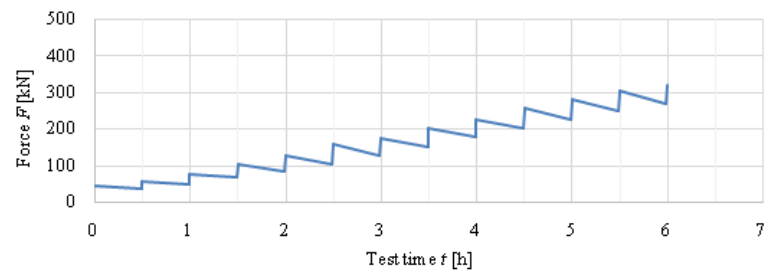

Fig. 6: Simplified loading process for model in Ansys

(Fig. 6). The material behavior of the model is selected as linear with respect to the Hooke's law. Whether the results will response to the experimental data, we can assume linear behavior and detect the elastic effect area.

\section{Results}

Firstly, the experimental data were evaluated. Since the transformation was measured only in the points as shows Fig. 2, and the maximal deformation cannot be measured directly, the approximation curve of 3rd order was used to evaluate the maximal deformation. The maximal deformation is located in the middle of the slab right under the center of the acting force.

Following results were obtained from solving numerical task with the parameters as described (Fig. 8). Deformation was observed in the same place as described before - in the middle of the slab, under the center of load area.

Deformation was not observed only in the center but also a shape of deflection basin was investigated. For this purpose, several deformations trough cross-section of slab (nodes 3-7-21-25 Fig. 2) in several times were evaluated. Experimental values were calculated as average from symmetrical values to remove the effect of uneven settlement. Experimental and numerical values were compared in the time $0.5 \mathrm{~h}$ (tab. 1. Fig. 9- left), 1.0h (tab. 2, fig.9 - right), 1.5 h (tabb. 3. Fig. 10 left) and $2.0 \mathrm{~h}$ (tab.b. 4. Fig. 10-right).

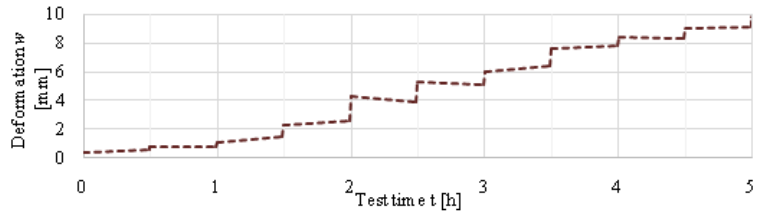

Fig. 7: Deformation evaluated from measured values from experimental testing

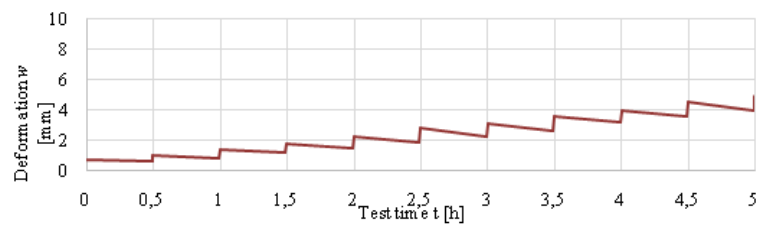

Fig. 8: Deformation evaluated from numerical model in Ansys

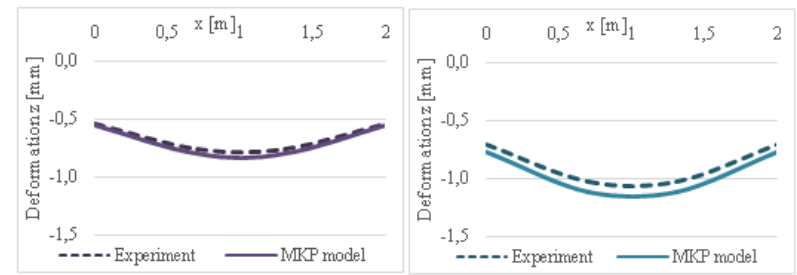

Fig. 9: Deformation evaluated from numerical model in Ansys

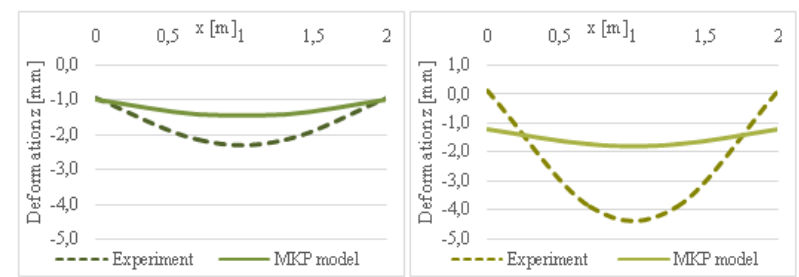

Fig. 10: Graphical comparison of deformations for time $t=1.5 \mathrm{~h}$ (left) and $2.0 \mathrm{~h}$ (right) 


\begin{tabular}{|c|c|c|c|c|}
\hline Point no. & 1 & 2 & 3 & 4 \\
\hline Measured value (experiment) $z[\mathrm{~mm}]$ & -0.537 & -0.760 & -0.760 & -0.537 \\
\hline Calculated value (MKP model) $z[\mathrm{~mm}]$ & -0.559 & -0.805 & -0.805 & -0.559 \\
\hline
\end{tabular}

Tab. 1: Deformation of slab in time $t=0.5 \mathrm{~h}$ under load $F=56.4 \mathrm{kN}$

\begin{tabular}{|c|c|c|c|c|}
\hline Point no. & 1 & 2 & 3 & 4 \\
\hline Measured value (experiment) $z[\mathrm{~mm}]$ & -0.704 & -1.030 & -1.030 & -0.704 \\
\hline Calculated value (MKP model) $z[\mathrm{~mm}]$ & -0.777 & -1.120 & -1.120 & -0.777 \\
\hline
\end{tabular}

Tab. 2: Deformation of slab in time $t=1.0 \mathrm{~h}$ under load $F=77.2 \mathrm{kN}$

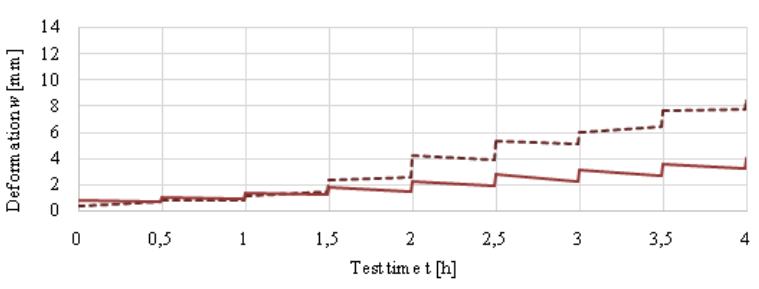

Fig. 11: Comparison of deformation evaluated from measured values from experimental testing and values calculated from numerical model in Ansys

\section{Discussion of Results}

To observe the area of the linear behavior of the experiment, the values evaluated from the experiment were compared with the linear model in Ansys (Fig. 11).

From the comparison (Fig. 11) is obvious, that the linear model does not consider nonlinear effects occurring in the real construction. Decrease of the applied force in the experiment was caused due to the deformation of the subsoil and cracking of the concrete but in the model is evident linear unloading path since the numerical model does not take into account the plastic deformations. Difference in shape of the deflection basin is more evident with rising time of the test(Fig. 12). The effect of lifting slab at edges was not as significant as in the experiment even though the contact was modeled. This phenomenon can be observed especially at values obtained at time $\mathrm{t}=2.0 \mathrm{~h}$ but it can be assumed that it will have ascent trend. In the model, the lifting of edges occurs, but overall vertical deformation is more significant in contrast to experiment and deflection basin is shallower due to the linear behavior of the slab unlike the experiment.

\section{Conclusion}

The aim of this paper was determining the area of the linear behavior on the experimental test results. For this reason, the Ansys model was created with the realistic geometry, characteristics and loading. The area of experiment where the linear stress-strain curve can

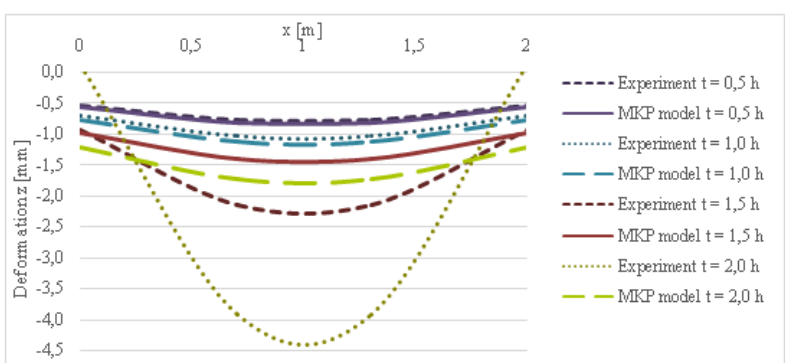

Fig. 12: Comparison of vertical deformation between FEM model and experiment for different times through cross - section of the slab

be successfully applied is in the comparison with size of the whole experiment pretty small. After time of 2 hours the deformation started to differs up to more than $100 \%$ as can be seen from graph (Fig. 11). On the other hand, the $326 \mathrm{kN}$ load responds to failure damage of the concrete slab, which is obvious that cannot be simulated by model reflecting Hooke's law only therefore attention has been paid to the first part of the test. The area up to time of 2 hours with load to $127.2 \mathrm{kN}$ was observed closer and numerical values were compared with the experimental values trough the cross - section of the slab (Fig. 12). From the comparison was revealed that the calculated deformation basin is more shallow than the experimental. This phenomenon does not appear until the load of $101.8 \mathrm{kN}$ and is related to the permanent damage of slab. To simulate this phenomenon more sophisticated model is required. Also the dimensions of the modeled area inflict changes in numerical deformations. It can be assumed that the overall vertical deformation should have increasing trend with bigger subsoil dimensions. In the paper dimensions of subsoil were small compared to the half - space so it would be observed on the models which dimensions are closer to the half - space since the soil model is based on the elastic half - space theory.

\section{Acknowledgment}

This outcome has been achieved with the financial support of the project GACR No. 16-08937S "State of 


\begin{tabular}{|c|c|c|c|c|}
\hline Point no. & 1 & 2 & 3 & 4 \\
\hline Measured value (experiment) $z[\mathrm{~mm}]$ & -0.934 & -2.143 & -2.143 & -0.934 \\
\hline Calculated value (MKP model) $z[\mathrm{~mm}]$ & -0.975 & -1.405 & -1.405 & -0.975 \\
\hline
\end{tabular}

Tab. 3: Deformation of slab in time $t=1.5 \mathrm{~h}$ under load $F=101.8 \mathrm{kN}$

\begin{tabular}{|c|c|c|c|c|}
\hline Point no. & 1 & 2 & 3 & 4 \\
\hline Measured value (experiment) $z[\mathrm{~mm}]$ & 0.126 & -3.910 & -3.910 & 0.126 \\
\hline Calculated value (FEM model) $z[\mathrm{~mm}]$ & -1.205 & -1.735 & -1.735 & -1.205 \\
\hline
\end{tabular}

Tab. 4: Deformation of slab in time $t=2.0$ hours under load $F=127.2 \mathrm{kN}$

stress and strain of fiber reinforced composites in interaction with the soil environment".

\section{References}

[1] FEDA, J. Tenseness of subsoil and calculation methods for calculation of final subsidence, Academia. 1974, 152 pages. (In Czech)

[2] KOLAR, V.and I. NEMEC. Modelling of Soilstructure Interaction. 1989, Elsevier, New York, USA. ISBN 04-449-8859-9.

[3] KRALIK, J. and N. JENDZELOVSKY. Contact problem of reinforced concrete girder and non-linear Winkler foundations. Geomechanics 93. 1994, pp. 233-236.

[4] ABOUtalebi, M., AlANi, A., RIZZUTO,J. and D. BECKETT. Structural behaviour and deformation patterns in loaded plain concrete ground-supported slabs. Structural Concrete. 2014, pp. 81-93. DOI: .

[5] HEGGER, J., SHERIF, G. A. and M. RICKER. Experimental Investigations on Punching Behavior of Reinforced Concrete Footings. ACI Structural Journal. 2006, pp. 604-613.

[6] KUERES, D., SIBURG, C., HERBRAND, M., CLASSEN, M. and J. HEGGER. Uniform Design Method for punching shear in flat slabs and column bases. Engineering Structures. 136.1 April 2017, pp. 149-164, DOI: .

[7] SIBURG, C. and J. HEGGER. Experimental investigations on the punching behaviour of reinforced concrete footings with structural dimensions. Structural Concrete. 15 (3). 2014, DOI: .

[8] CAJKA, R., LABUDKOVA, J. and P. MYNARCIK. Numerical solution of soil - foundation interaction and comparison of results with experimetal measurements. International Journal of GEOMATE. Volume 11, Issue 1, 2016, pp. 2116 - 2122.
[9] CAJKA, R., KRIVY, V. and O. SEKANINA. Design and Development of a Testing Device for Experimental Measurements of Foundation Slabs on the Subsoil. Transactions of the $V A \breve{a B}$ - Technical University of Ostrava, Construction Series. 2011, pp. 1 -5, DOI:.

[10] CAJKA, R. and J. LABUDKOVA. Dependence of deformation of a plate on the subsoil in relation to the parameters of the $3 \mathrm{D}$ model. International Journal of Mechanic. 2014, pp. 208 - 21, ISSN: 19984448.

[11] CAJKA, R., LABUDKOVA, J. and P. MYNARCIK. Numerical solution of soil - foundation interaction and comparison of results with experimetal measurements. International Journal of GEOMATE, 11(1). 2016, pp. 2116 - 2122.

[12] LABUDKOVA, J. and R. CAJKA. Experimental measurements of subsoil-structure interaction and 3D numerical models. Perspectives in Science. 2016, pp. 240 - 246. DOI: .

[13] LAHUTA H., HRUBESOVA E., DURIS L. and T. PETRASOVA. Behaviour subsoil of slab foundation under loading. International Multidisciplinary Scientific GeoConference Surveying Geology and Mining Ecology Management. SGEM. 2(1), 2015, pp. 119 - 126, ISSN 1314 - 2704.

[14] SUCHARDA, O., BILEK, V., SMIRAKOVA M., KUBOSEK, J. and R. CAJKA. Comparative Evaluation of Mechanical Properties of FibreReinforced Concrete and Approach to Modelling of Bearing Capacity Ground Slab. Periodica Polytechnica Civil Engineering. 2017, pp. 972 - 986. ISSN 1587-3773. Available at: https://pp. bme.hu/ci/article/view/10688.

[15] HALVONIK, R.J. and J. FILLO. The Maximum Punching Shear Resistance of Flat Slabs. Procedia Engineering. 65, 2013, pp. 376-381, ISSN 18777058 .

[16] KOtsovou, M.G., KOTsovos, M., G. and E. VOUGIOUKAS. Assessment of design meth- 
ods for punching through numerical experiments. Computers and Concrete. 17(3), DOI: .

[17] CSN EN 1992-1-1, Eurocode 2: Design of concrete structures - Part 1-1: General reles and rules for buildings, 2006.

[18] EN 1997-1 (2004) (English): Eurocode 7: Geotechnical design - Part 1: General rules. [Authority: The European Union Per Regulation 305/2011, Directive 98/34/EC, Directive 2004/18/EC].

[19] ZIENKIEWICZ, O.C. The Finite Element Method in Engineering Science. 1971, London: McGrawHill. 